\title{
Septic serum mediates inflammatory injury in human umbilical vein endothelial cells via reactive oxygen species, mitogen activated protein kinases and nuclear factor- $\kappa B$
}

\author{
SHOUZHU XU ${ }^{1}$, YU YAN $^{1}$, ZHIJIAO YAN ${ }^{1}$, JIE XU $^{1}$, BAONING QI ${ }^{1}$, JUAN LI $^{1}$, \\ ZHIGANG ZHANG ${ }^{1}$, YUANPING HAN $^{1}$ and JING ZHAO ${ }^{2}$ \\ ${ }^{1}$ Department of Public Health, ${ }^{2}$ College of Acupuncture and Moxibustion, \\ Shaanxi University of Chinese Medicine, Xianyang, Shaanxi 712046, P.R. China
}

Received May 5, 2020; Accepted October 5, 2020

DOI: $10.3892 / \mathrm{ijmm} .2020 .4785$

\begin{abstract}
Sepsis-induced blood vessel dysfunction is mainly caused by microvascular endothelial cell injury. However, the mechanism underlying sepsis-induced endothelial cell injury remains unclear. The present study hypothesized that sepsis-induced inflammatory injury of endothelial cells may be the first step of endothelial barrier dysfunction. Therefore, the present study aimed to uncover the mechanism underlying the inflammatory effects of sepsis. A rat model of cecal ligation and puncture-induced sepsis was established, and septic serum was collected. Subsequently, human umbilical vein endothelial cells (HUVECs) were treated with the isolated septic or normal serum. HUVEC viability was assessed using a Cell Count Kit-8 assay. Furthermore, transmission electron microscopy and reverse transcription-quantitative PCR (RT-qPCR) analysis were carried out to observe the cell morphology and determine the mRNA expression levels in septic serum-induced HUVECs. The protein expression levels were evaluated by western blot analysis, and the secretion of the inflammatory factors interleukin (IL)- $1 \beta$, IL-6 and tumor necrosis factor (TNF)- $\alpha$ was determined by ELISA. Additionally, reactive oxygen species (ROS) generation and nuclear factor (NF)- $\mathrm{\kappa B}$ nuclear translocation were observed under a fluorescence microscope. The results of the present study demonstrated that HUVEC viability was significantly decreased following 12- or 24-h treatment with septic serum. In addition, chromatin condensation, mitochondrial vacuolization and endoplasmic reticulum degranulation were observed following treatment with septic serum. Furthermore, the
\end{abstract}

Correspondence to: Dr Jing Zhao, College of Acupuncture and Moxibustion, Shaanxi University of Chinese Medicine, 1 Shiji Avenue, Xi'an-Xianyang New Economic Zone, Xianyang, Shaanxi 712046, P.R. China

E-mail: zhaojing_1207@126.com

Key words: sepsis, human umbilical vein endothelial cells, inflammatory injury secretion levels of IL-1 $\beta$, IL- 6 and TNF- $\alpha$ were increased in septic serum-stimulated HUVECs. Septic serum treatment also enhanced superoxide anion generation, promoted extracellular signal regulated kinase 1/2 (ERK1/2), N-terminal kinase (JNK) and p38 mitogen-activated protein kinase (p38) phosphorylation, and increased NF- $\kappa \mathrm{B}$ levels in the nuclei of HUVECs. Finally, pre-treatment of HUVECs with the antioxidant N-acetylcysteine, the ERK1/2 inhibitor PD98059, the p38 inhibitor SB203580, the JNK inhibitor SP610025 or the NF- $\kappa \mathrm{B}$ inhibitor pyrrolidine dithiocarbamate restored the septic serum-induced IL- $1 \beta$, IL- 6 and TNF- $\alpha$ expression. In conclusion, the results of the current study suggested that the septic serum-induced endothelial cell injury may be mediated by increasing ROS generation, activation of mitogen-activated protein kinases and NF- $\kappa \mathrm{B}$ translocation.

\section{Introduction}

Sepsis may promote systemic inflammatory injury of the blood vessels, resulting in microvascular endothelial cell dysfunction and injury (1-3). Microvascular dysfunction is of great importance in the clinic and has been associated with increasing mortality when the dysfunction persists for a long time (4-7). Endothelial dysfunction is considered to be an early event for a range of vascular diseases (such as atherosclerosis, hypertension and myocardial ischemia) and it has been reported that inflammation is involved in this pathological process $(8,9)$. Results from clinical and scientific studies have demonstrated that septic microvascular dysfunction may be mediated by a number of factors and processes, including the activation of leukocytes (10), the secretion of inflammatory cytokines (11) and the exposure of microvascular cells to harmful leukocyte-derived molecules (12). In addition, it has been suggested that the local production of inflammatory factors in vascular cells may exert a direct and significant effect on the pathological process of sepsis (13). The expression of several types of inflammatory cytokines, including interleukin (IL)- $1 \beta$, IL- 6 and tumor necrosis factor (TNF- $\alpha$ ) may be induced by sepsis $(14,15)$. Furthermore, inflammatory cell infiltration and the oxidative stress-mediated generation of reactive oxygen species (ROS) may promote blood vessel damage, 
activation of mitogen-activated protein kinases (MAPKs) and translocation of nuclear factor- $\kappa \mathrm{B}(\mathrm{NF}-\kappa \mathrm{B})$ into the cell nucleus $(16,17)$. However, the specific mechanism underlying the sepsis-induced pro-inflammatory responses remains unclear. Therefore, the present study aimed to determine the mechanism underlying the sepsis-induced inflammatory injury of HUVECs by focusing on the effects of ROS, MAPKs and $\mathrm{NF}-\kappa \mathrm{B}$.

\section{Materials and methods}

Reagents. Dulbecco's modified Eagle's medium (DMEM) was obtained from HyClone (Cytiva), and fetal bovine serum (FBS) was purchased from Gibco. TRIzol ${ }^{\circledR}$ was obtained from Invitrogen (Thermo Fisher Scientific, Inc.). PrimeScript ${ }^{\mathrm{TM}}$ 1st strand cDNA Synthesis kit and SYBR ${ }^{\circledR}$ Premix Ex Taq were obtained from Takara Biotechnology Co., Ltd.The extracellular signal regulated kinase 1/2(ERK 1/2) inhibitor PD98059, the p38 inhibitor SB203580, the antioxidant N-acetylcysteine (NAC) and the NF- $\mathrm{B}$ inhibitor pyrrolidine dithiocarbamate (PDTC) were purchased from Sigma-Aldrich, Merck KGaA. The following antibodies were used in the present study: Rabbit monoclonal anti- $\beta$-actin (cat. no. NC021; Zhuangzhi Biotech), anti-NF- $\mathrm{B}$ (cat. no. ab16502; Abcam), anti-lamin B1 (cat. no. AF1408), anti-NF-кB p65 (cat. no. SN368), anti-ERK1/2 (cat. no. AF1051), anti-phospho-ERK1/2 (cat. no. AF5851), anti-JNK (cat. no. AJ518), anti-phospho-JNK cat. no. AJ516) (all from Beyotime Institute of Biotechnology), anti-phospho-p38 (cat. no. 9216), anti-p38 (cat. no. 8690) (both from Cell Signaling Technology, Inc.). The HRP-conjugated anti-mouse IgG (cat. no. CW0102S) and anti-Rabbit IgG (cat. no. CW0103S) secondary antibodies were obtained from CW Biotech, Co., Ltd. Furthermore, 2',7'-dichlorodihydrofluororescein diacetate $\left(\mathrm{H}_{2} \mathrm{DCF}-\mathrm{DA}\right)$ was obtained from Beyotime Institute of Biotechnology, and ELISA kits for detecting human IL-1 $\beta$ (cat. no. F01220), IL-6 (cat. no. F01310) and TNF- $\alpha$ (cat. no. F02810) were obtained from Westang. All other chemicals used in the experiments were of analytical grade.

Isolation of septic serum. Male Sprague-Dawley (SD) rats (age, 6 weeks; n=16; weight, 150-170 g; purchased from Chengdu Dossy Experimental Animals Co., Ltd.) were randomly divided into two groups. The animals were maintained under pathogen-free conditions (temperature, $25^{\circ} \mathrm{C}$; humidity, $50 \%$; 12-h light/dark cycle) and had free access to food and water. A cecal ligation and puncture-induced sepsis rat model was established as previously described (18). Briefly, rats were fasted overnight (12 h) one day prior surgery (the body weight loss after fasting was 3-8 g) and anesthetized by intraperitoneal injection of $10 \%$ chloral hydrate $(200 \mathrm{mg} / \mathrm{kg}$ body weight). None of the rats presented with signs of peritonitis following injection. Once the rats appeared unconscious with normal breath, the lower abdomen was incised, and the cecum was ligated with 2-0 surgical silk, pierced with an 18-gauge needle, gently compressed until fecal matter was extruded, and returned to the abdominal cavity. Finally, the abdomen was completely closed with 2-0 surgical silk. Animals in the sham group underwent exactly the same procedure without the cecal puncture. After $24 \mathrm{~h}$, the rats were euthanized with intraperitoneal injection of pentobarbital sodium $(200 \mathrm{mg} / \mathrm{kg})$; death was confirmed by the occurrence of cardio-respiratory arrest, and $\sim 10 \mathrm{ml}$ of serum was collected from the abdominal aorta. In the current study, symptoms such as pain, weight loss, loss of appetite or weakness were set as humane endpoints; however, no animal was sacrificed prior the completion of the experiments due to reaching these endpoints. All experimental procedures in animals were carried out according to international, national and institutional regulations, and were approved by the Shaanxi University of Chinese Medicine (approval no. 201801115).

Cell culture and treatment. HUVECs were obtained from Cobioer Biosciences Co., Ltd. (lot no. CBP60340) and cultured in DMEM supplemented with $10 \% \mathrm{FBS}$ at $37^{\circ} \mathrm{C}$ with $5 \% \mathrm{CO}_{2}$. Prior to treatment, cells $\left(1-1.5 \times 10^{7}\right)$ were cultured in serum-free medium for an additional $12 \mathrm{~h}$. HUVECs in the septic serum-treatment group were cultured in DMEM supplemented with $10 \%$ septic serum for 12 or $24 \mathrm{~h}$, whereas those in the control group were cultured in DMEM with $10 \%$ control serum. For the cell signaling pathway investigation, the cells were pre-treated with specific inhibitors for $1 \mathrm{~h}$, followed by treatment with $10 \%$ septic serum. The concentrations of the specific inhibitors were as follows: $20 \mu \mathrm{M}$ ERK 1/2 inhibitor PD98059; $10 \mu \mathrm{M}$ p38 inhibitor SB203580; $20 \mu \mathrm{M}$ JNK inhibitor SP600125; $10 \mu \mathrm{M}$ antioxidant NAC; and $10 \mu \mathrm{M} \mathrm{NF- \kappa B}$ inhibitor PDTC, as previously described (19).

Cell viability assay. Following treatment, HUVEC viability was assessed using a Cell Counting Kit (CCK-8; cat. no. C0037; Beyotime Institute of Biotechnology). Briefly, cells (1-1.5x10 $)$ were seeded into a 96-well plate, and $10 \mu \mathrm{lCCK}-8$ solution was added into each well, followed by incubation at $37^{\circ} \mathrm{C}$ for an additional $4 \mathrm{~h}$. Subsequently, the optical density (OD) of each well was measured at $450 \mathrm{~nm}$ using a microplate reader (Molecular Devices, LLC). The mean OD value from six wells was obtained, and the cell viability was calculated as the percentage relative to the OD values in the control group.

Cell morphology analysis. Cell morphology was examined using a JEM-101 (Jeol Electron Inc.) transmission electron microscope (TEM). At $12 \mathrm{~h}$ following treatment, cells were collected by centrifugation ( $150.3 \mathrm{x}$ g; $5 \mathrm{~min})$, washed three times with PBS and fixed in $1 \%$ paraformaldehyde supplemented with $2 \%$ glutaraldehyde for $24 \mathrm{~h}$ at $4^{\circ} \mathrm{C}$. Fixed cells were further treated with $1 \%$ osmium tetroxide for $2 \mathrm{~h}$ at $25^{\circ} \mathrm{C}$, dehydrated in graded ethanol $(50,70,80,90$ and $100 \%$ for $10 \mathrm{~min} / \mathrm{step}$ ) and embedded in araldite. Ultrathin sections $\left(70 \mathrm{~nm}\right.$ ) were cut, stained with uranyl acetate for $30 \mathrm{~min}$ at $25^{\circ} \mathrm{C}$, washed three times with double distilled water, and stained with lead citrate for $10 \mathrm{~min}$ at $25^{\circ} \mathrm{C}$, followed by washing three times with double distilled water. Finally, the cell morphology was observed under a JEM-101 TEM (x8,000 magnification; JEOL Ltd.), and three fields were observed per sample.

Reverse transcription- $q P C R(R T-q P C R)$. Following treatment, HUVECs $\left(1 \times 10^{5}\right.$ cells/well) were washed twice with ice-cold PBS, and total RNA was extracted using TRIzol ${ }^{\circledR}$ reagent according to the manufacturer's instructions. The concentration of the total RNA was determined by measuring the absorbance at $260 \mathrm{~nm}$. Subsequently, total RNA was reverse-transcribed 
into cDNA using a PrimeScript ${ }^{\mathrm{TM}}$ 1st strand cDNA Synthesis Kit. The cDNA of the target genes was amplified using the SYBR $^{\circledR}$ Premix Ex Taq on the Mx3000P quantitative PCR system (Stratagene; Agilent Technologies, Inc.). The primer sequences used were as follows: Human IL-1 $\beta$ forward, 5'-CATTGAGCCTCATGCTCTGTT-3' and reverse, 5'-CGC TGTCTGAGCGGATGAA-3'; human IL-6 forward, 5'-TTC GGTCCAGTTGCCTTCTC-3' and reverse, 5'-TCACCAGGC AAGTCTCCTCA-3'; human TNF- $\alpha$ forward, 5'-GCTGCA CTTTGGAGTGATCG-3' and reverse, 5'-GCTTGAGGGTTT GCTACAACA-3'; and human GAPDH forward, 5'-TGTGGG CATCAATGGATTTGG-3' and reverse, 5'-ACACCATGT ATTCCGGGTCAAT-3'. The expression levels of the target mRNAs were normalized to those of GAPDH. All samples were run in triplicate and analyzed using the $2^{-\Delta \Delta C q}$ method as previously described (20).

ELISA. The current knowledge of the pathophysiology of sepsis suggests that patients present with hyperinflammation, and excessive production of inflammatory markers (such as IL-1 $\beta$, IL- 6 and TNF- $\alpha$ ) occurs throughout the course of sepsis (21). In the current study, HUVECs $\left(1-1.5 \times 10^{5}\right)$ were cultured in 96-well plates and stimulated with septic serum for $12 \mathrm{~h}$. Subsequently, the supernatant was collected by centrifugation $\left(900 \mathrm{x} \mathrm{g} ; 10 \mathrm{~min}\right.$ at $\left.4^{\circ} \mathrm{C}\right)$, and the serum levels of IL-1 $\beta$, IL-6 and TNF- $\alpha$ were evaluated using specific ELISA kits according to the manufacturer's instructions. Subsequently, the optical density (OD) of each well was measured at $490 \mathrm{~nm}$ using a microplate reader (Molecular Devices, LLC).

Measurement of superoxide anion generation. HUVECs $\left(1-1.5 \times 10^{7}\right)$ were cultured in 6-well plates and treated with septic serum for $12 \mathrm{~h}$. Subsequently, the cells were supplemented with $10 \mu \mathrm{M} \mathrm{H}_{2}$ DCF-DA for $1 \mathrm{~h}$ and washed with ice-cold PBS three times. Fluorescence images were acquired at an excitation wavelength of $488 \mathrm{~nm}$ and an emission wavelength of $525 \mathrm{~nm}$ under a fluorescence microscope (x200 magnification; Olympus Corporation), and six fields were observed per well. Fluorescence intensity was calculated and analyzed from the fluorescence images with the Image-pro plus software (Version X; Media Cybernetics, Inc.). The relative fluorescence intensity was calculated as the mean value of six independent experiments.

Western blotting. Following treatment with septic or normal serum in 6-well plates, cells were washed twice with ice-cold PBS and lysed using a lysis buffer (100 $\mu \mathrm{l} /$ well; Beyotime Institute of Biotechnology) supplemented with a protease inhibitor cocktail and phosphatase inhibitors (Roche Diagnostics). The nuclear proteins were extracted using a NE-PER Nuclear Cytoplasmic Extraction Reagent kit (Pierce; Thermo Fisher Scientific, Inc.) according to the manufacturer's instructions. Briefly, treated cells were lysed with $200 \mu \mathrm{l}$ cytoplasmic extraction reagent I followed by the addition of $11 \mu \mathrm{l}$ cytoplasmic extraction reagent II for $5 \mathrm{sec}$. Subsequently, the cells were incubated on ice for $1 \mathrm{~min}$, centrifuged $(10,000 \mathrm{x} \mathrm{g})$ at $4^{\circ} \mathrm{C}$ for $5 \mathrm{~min}$, and the supernatant fractions (cytoplasmic extracts) were transferred into a prechilled tube. The insoluble pellet fraction was resuspended in $100 \mu 1$ nuclear extraction reagent followed by vortexing for $15 \mathrm{sec}$, incubation on ice for

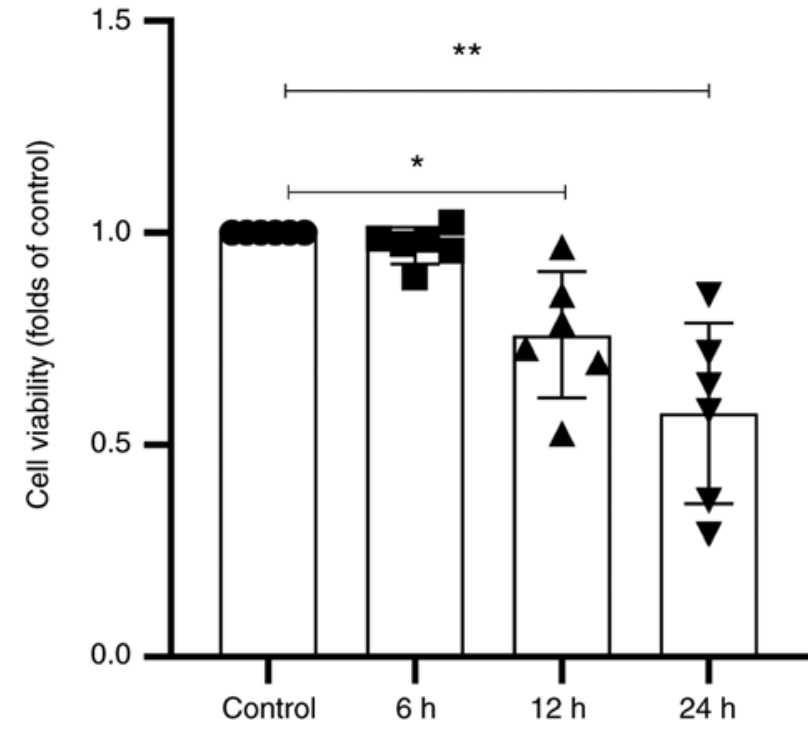

Figure 1. Septic serum decreases the viability of human umbilical vein endothelial cells. The cells were incubated with septic serum for 0-24 h, and the cell viability was determined by Cell Counting Kit- 8 assay. The data from six independent experiments are expressed as the mean \pm SEM. ${ }^{*} \mathrm{P}<0.05$ and ${ }^{* *} \mathrm{P}<0.01$.

$10 \mathrm{~min}$ and centrifugation $(12,000 \mathrm{xg})$ at $4^{\circ} \mathrm{C}$ for $10 \mathrm{~min}$. The resulting supernatant was used for subsequent experiments. Protein concentration was determined with a BCA protein assay kit (Bio-Rad Laboratories, Inc.). Equal amounts of protein extracts $(30 \mu \mathrm{g})$ were separated by $10 \%$ SDS-PAGE and transferred to polyvinylidene fluoride membranes (pore size, $0.45 \mu \mathrm{m}$; Cytiva). The membranes were incubated with antibodies against $\beta$-actin $(1: 2,000), \mathrm{NF}-\kappa \mathrm{B}(1: 2,500)$, lamin B1 $(1: 1,500)$, JNK $(1: 1,500)$, phospho-JNK (1:800), p38 (1:1,000), phospho-p38 (1:500), ERK1/2 (1:1,000) or phospho-ERK1/2 (1:800) overnight at $4^{\circ} \mathrm{C}$. Following washing with TBS $+0.25 \%$ Tween-20 three times, the membranes were incubated with the corresponding secondary antibody $(1: 2,500)$ for $3 \mathrm{~h}$ at $25^{\circ} \mathrm{C}$, and the immune complexes were enhanced by chemiluminescence (Merck Life Science UK, Ltd.). The intensity of the bands was determined by scanning and quantification using the Bio-Rad Gel Doc ${ }^{\mathrm{TM}} 2000$ imaging system (Bio-Rad Laboratories, Inc.).

Statistical analysis. The data are presented as the mean \pm standard error of the mean. The normality and homogeneity of these data were tested, and the differences among groups were assessed with one-way ANOVA followed by Dunnett's or non-parametric Kruskal-Wallis analysis followed by Dunn's test using GraphPad Prism 8.3 software (GraphPad Software, Inc.). $\mathrm{P}<0.05$ was considered to indicate a statistically significant difference.

\section{Results}

Septic serum attenuates HUVEC viability. In the present study, cell viability was assessed to evaluate the toxic effects of septic serum. As demonstrated in Fig. 1, the viability of HUVECs was significantly decreased following treatment with septic serum for 12 and $24 \mathrm{~h}$. This suggested that 


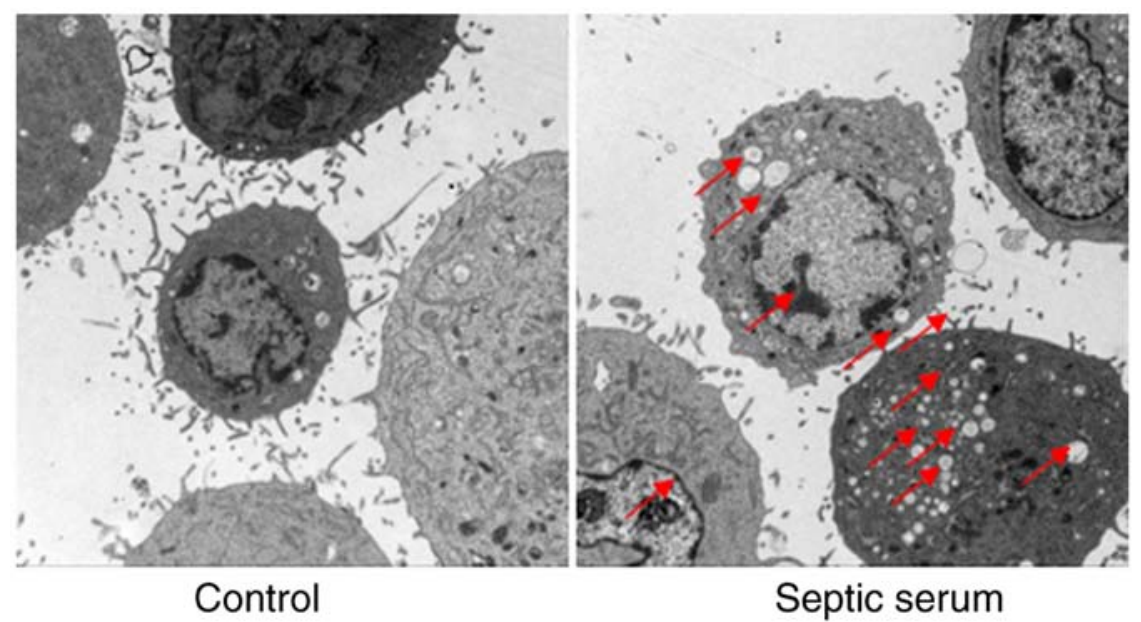

Figure 2. Septic serum induces injury in human umbilical vein endothelial cells. The cells were subjected to septic serum treatment for $12 \mathrm{~h}$, and the morphological changes were observed by transmission electron microscopy. Magnification, x8,000.

sepsis exerted harmful effects on vascular endothelial cells; according to these results, $12 \mathrm{~h}$ was selected the treatment time for subsequent experiments.

Septic serum induces HUVEC injury. To evaluate the effects of septic serum on endothelial cell injury, HUVECs were observed under TEM following treatment with septic serum. As presented in Fig. 2, cells treated with the normal serum exhibited normal morphology. However, when cells were treated with septic serum for $12 \mathrm{~h}$, harmful morphological changes were identified, including chromatin condensation, mitochondrial vacuolization and endoplasmic reticulum degranulation. These results further demonstrated that septic serum mediated HUVEC injury.

Septic serum stimulates the expression of inflammatory cytokines by HUVECs. In the present study, the mRNA and protein levels of IL-1 $\beta$, IL- 6 and TNF- $\alpha$ were determined by RT-qPCR and ELISA, respectively. The results demonstrated that the mRNA expression levels of IL-1 $\beta$, IL- 6 and TNF- $\alpha$ were significantly increased following treatment of HUVECs with septic serum compared with those in the normal serum-treated cells (Fig. 3A-C). Consistent with these results, ELISA demonstrated that the protein secretion levels of IL-1 $\beta$, IL-6 and TNF- $\alpha$ in the culture medium were significantly increased following treatment of HUVECs with septic serum compared with those in the medium collected from cells treated with normal serum (Fig. 3D-F).

Septic serum promotes ROS generation, ERK1/2 and p38 phosphorylation, and the translocation of $N F-\kappa B$ in HUVECs. As demonstrated in Fig. 4A, the intracellular ROS generation was notably enhanced in HUVECs treated with septic serum compared with that in the control cells. Furthermore, western blotting results demonstrated that the levels of phosphorylation of ERK1/2, p38 and JNK, and the protein levels of NF- $\mathrm{KB}$ p65 in the cell nuclei were markedly increased after cell stimulation with septic serum for $12 \mathrm{~h}$ compared with those in the control group (Fig. 4B-E). Immunofluorescence staining also revealed that septic serum promoted NF- $\mathrm{\kappa B}$ translocation into HUVEC nuclei (Fig. 4F). Additionally, ELISA results demonstrated that the secretion levels of IL-1 $\beta$, IL- 6 and TNF- $\alpha$ were significantly decreased in the culture medium isolated from HUVECs pre-treated with the ERK1/2 inhibitor PD98059, the p38 inhibitor SB203580, the JNK inhibitor SP610025, the NF- $\mathrm{kB}$ inhibitor PDTC or the antioxidant NAC for $1 \mathrm{~h}$ compared with those in cells treated with septic serum alone (Fig. 5). These results indicated that ROS, MAPKs and the NF- $\kappa B$ signaling pathway may be involved in septic serum-induced inflammation in HUVECs.

\section{Discussion}

Endothelial cells are considered to be a crucial link between the cardiovascular and immune systems, and an essential and active component of the immune response (22). In sepsis, multiple organ dysfunction is partially caused by systemic inflammation-mediated microvascular endothelial cell injury (23-25). Furthermore, it has been revealed that the high levels of circulating endothelial cells and soluble markers associated with endothelial cell damage may indicate vascular injury, and are highly associated with severe sepsis and high mortality (26). In the current study, a sepsis rat model was established to investigate the effects and mechanism of sepsis on endothelial cell injury. The results demonstrated that treatment of HUVECs with septic serum induced the expression of IL- $1 \beta$, IL- 6 and TNF- $\alpha$, suggesting that the in vitro model mimicked the in vivo processes.

Sepsis is characterized by the activation of inflammation via several mechanisms, including severe oxidative stress-induced endothelial cell damage (27-29), and ROS-associated molecular signature predicts survival in patients with sepsis (30). ROS generation occurs during the onset of the inflammatory cascade (31). The results of the current study demonstrated that ROS generation was involved in the inflammatory effects of septic serum, as high levels of ROS were detected in HUVECs following treatment with septic serum, whereas pre-treatment with NAC significantly attenuated the sepsis-mediated expression of the inflammatory factors IL- $1 \beta$, IL- 6 and TNF- $\alpha$. It has been suggested that ROS serves a crucial role in the activation of proinflammatory mediators such as MAPKs, NF- $\kappa B$ and NLRP3 inflammasomes $(32,33)$. Dysregulation of ROS generation 
A

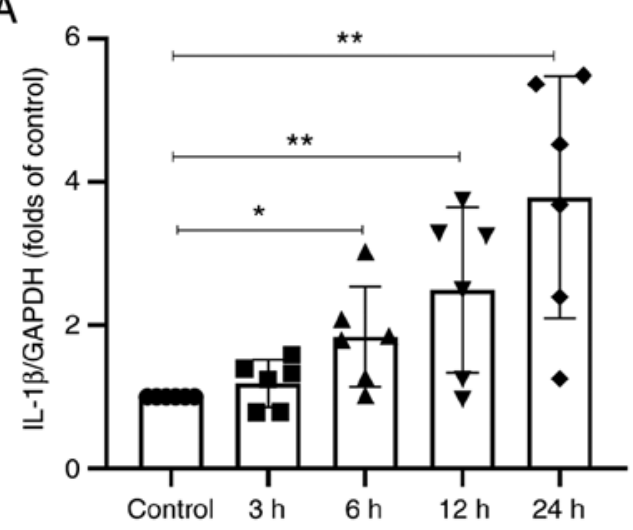

B

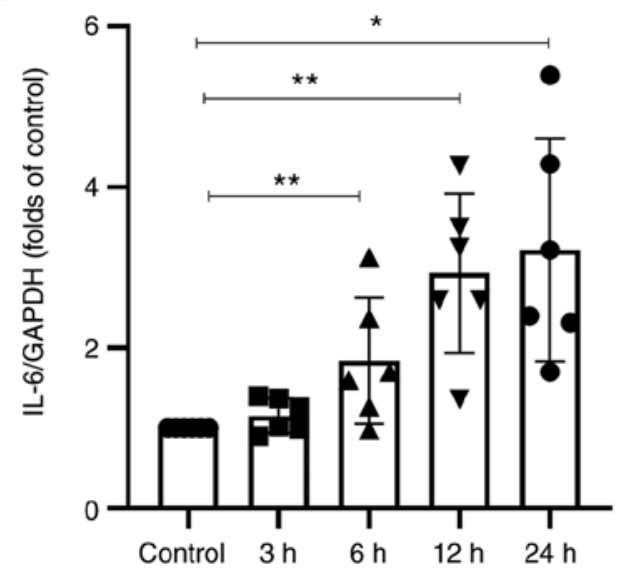

C

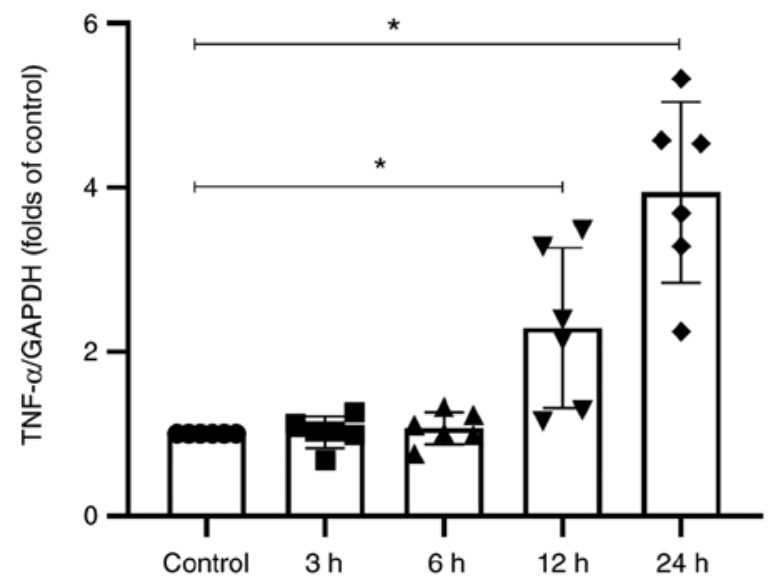

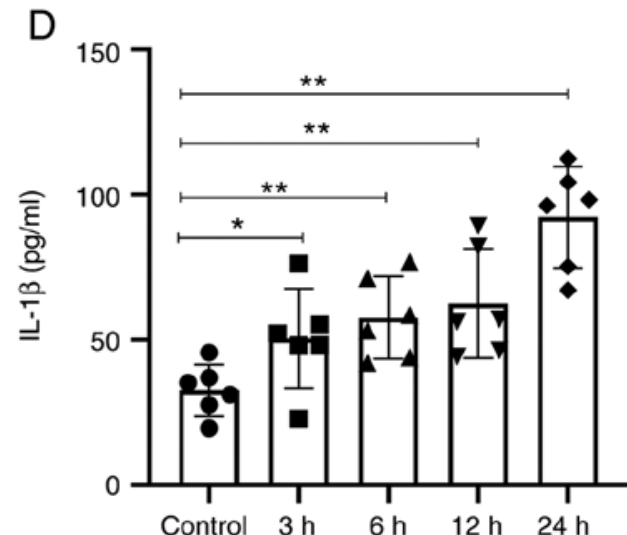

$E$

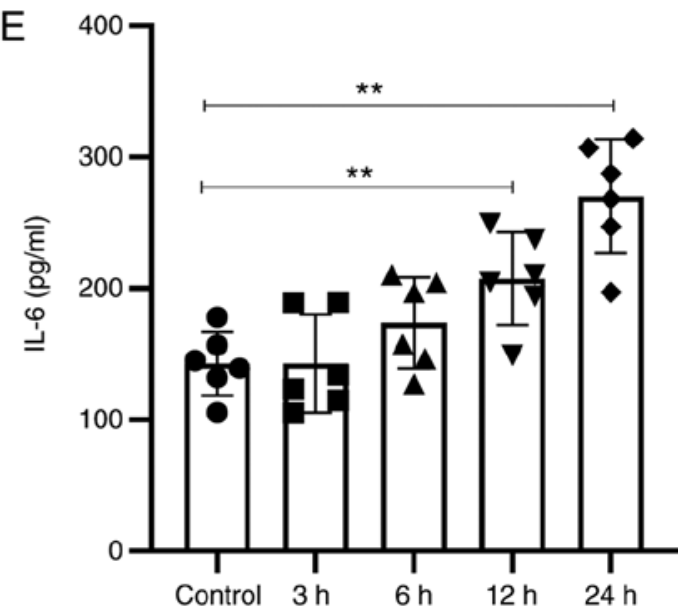

$\mathrm{F}$

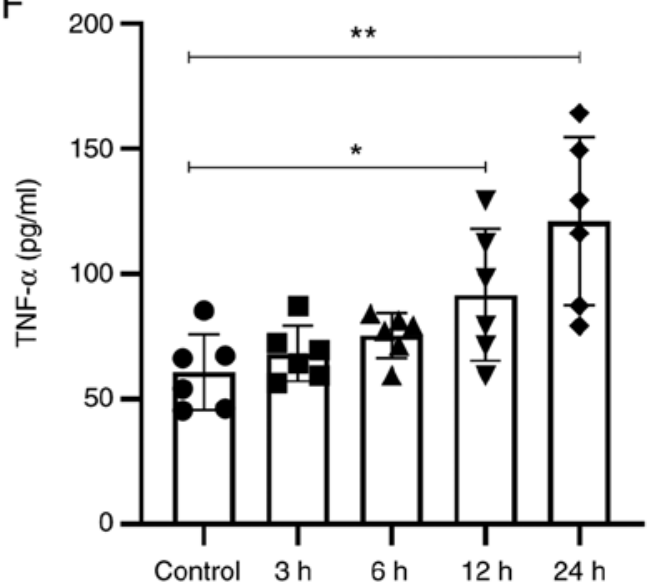

Figure 3. Septic serum increases mRNA and protein expression levels of IL-1 $\beta$, IL-6 and TNF- $\alpha$ in human umbilical vein endothelial cells. The cells were subjected to septic serum treatment for 0-24 h. (A) IL-1 $\beta$, (B) IL-6 and (C) TNF- $\alpha$ mRNA expression levels were determined by reverse transcription-quantitative PCR. (D) IL-1 $\beta$, (E) IL-6 and (F) TNF- $\alpha$ protein levels were determined by ELISA. The data from six independent experiments are expressed as the mean \pm SEM. ${ }^{*} \mathrm{P}<0.05$ and ${ }^{* *} \mathrm{P}<0.01$.

or insufficient ROS scavenging may result in the oxidation of a range of biomolecules, such as hypoxia-inducible factor $1 \alpha$, AMPK and NF- $\kappa \mathrm{B}$ inducing kinase, and the structural modification of proteins triggering signaling cascades, including the MAPK, NF- $\kappa \mathrm{B}$ and PI3K/AKT signaling pathways, leading to the progression of inflammatory diseases $(34,35)$. In the present study, increased levels of phosphorylated ERK1/2 and p38, and translocation of NF- $\kappa \mathrm{B}$ to the nucleus were observed following stimulation of HUVECs with septic serum compared with those observed in the control cells. MAPKs and the NF- $\kappa \mathrm{B}$ signaling serve a pivotal role in inflammation (17,36-40), whereas the activation of $N F-\kappa B$ regulates the expression of a number of inflammatory cytokines $(41,42)$. In the present study, treatment of HUVECs with selective ERK1/2, p38 MAPK and NF- $\kappa$ B inhibitors significantly suppressed the septic serum-induced secretion of inflammatory factors.

In conclusion, the results of the present study demonstrated that septic serum mediated endothelial cell injury via increasing ROS generation, activating MAPKs and promoting $\mathrm{NF}-\kappa \mathrm{B}$ translocation (Fig. 6). These results may provide a 
A
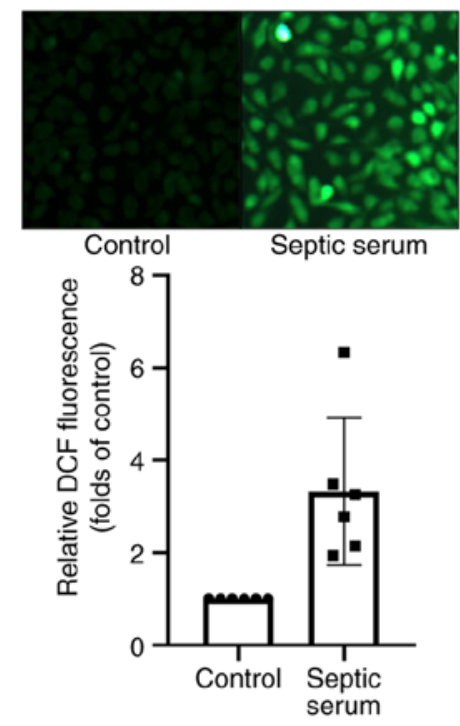

B
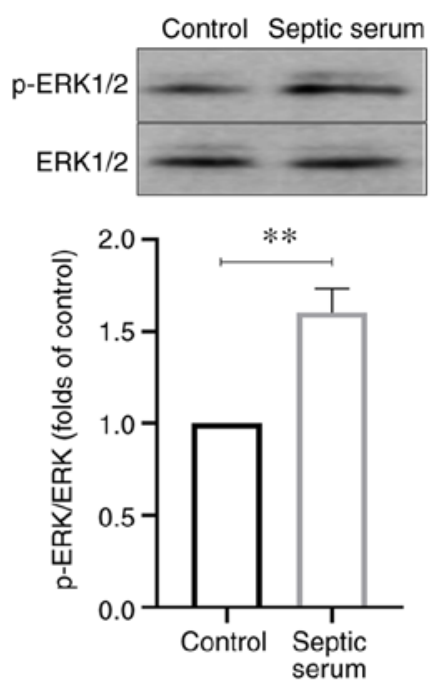
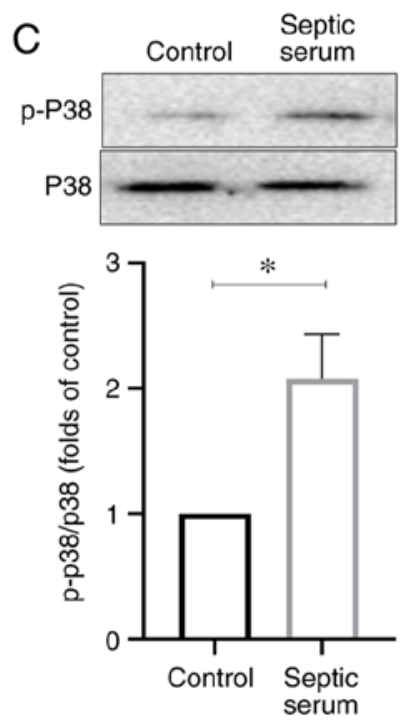

D
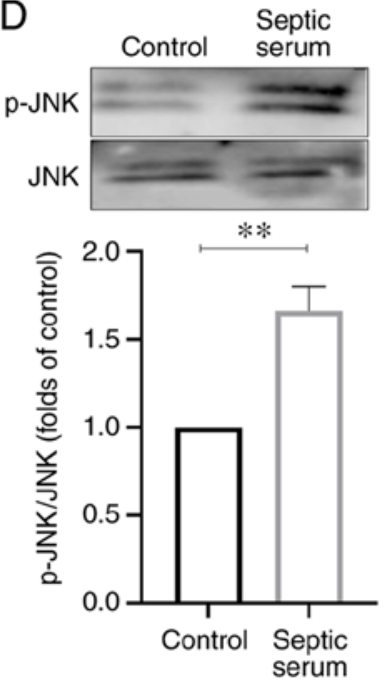

$\mathrm{E}$
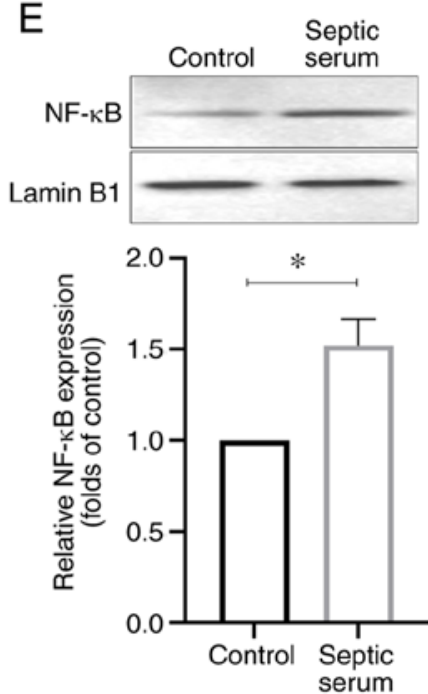

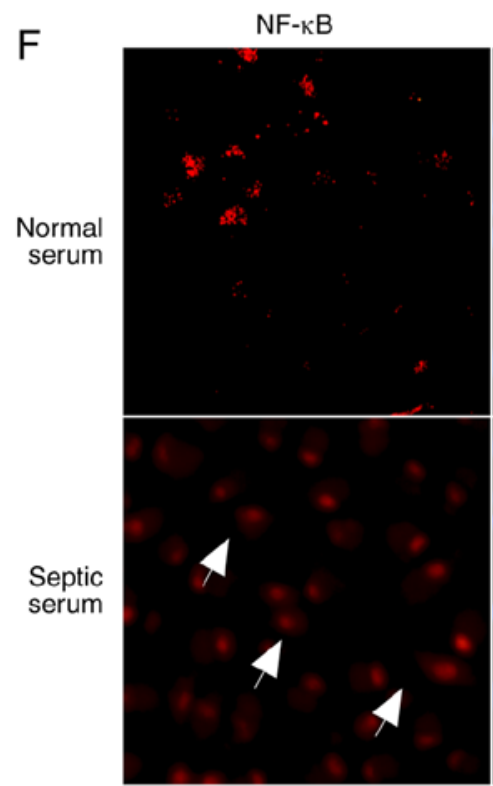

DAPI
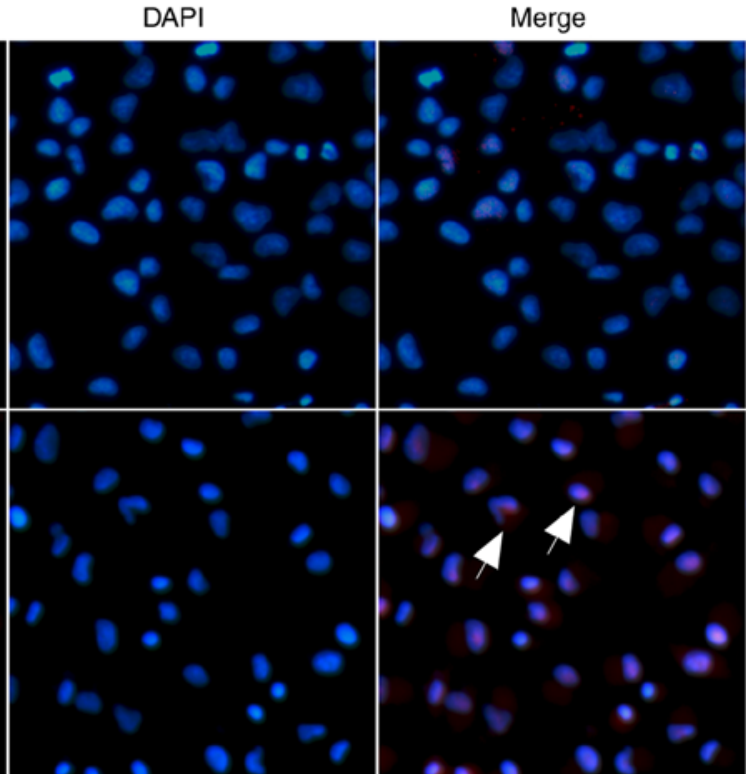

Figure 4. Septic serum increases the generation of ROS, activates MAPKs and promotes NF- $\kappa$ B transduction in HUVECs. (A) The cells were subjected to septic serum treatment for $12 \mathrm{~h}$, and ROS generation was determined by fluorescence microscopy. Magnification, x200. (B-E) Protein phosphorylation levels of

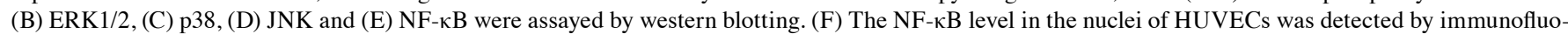
rescence staining. Red, NF- $\kappa B$ subunit $\mathrm{p} 65$; blue, nucleus. Data are expressed as the mean $\pm \mathrm{SEM}$ from three independent experiments. ${ }^{*} \mathrm{P}<0.05$ and ${ }^{* *} \mathrm{P}<0.01$. DCF, 2',7'-dichlorodihydrofluororescein diacetate; ROS, reactive oxygen species; p-, phosphorylated; HUVECs, human umbilical vein endothelial cells. 

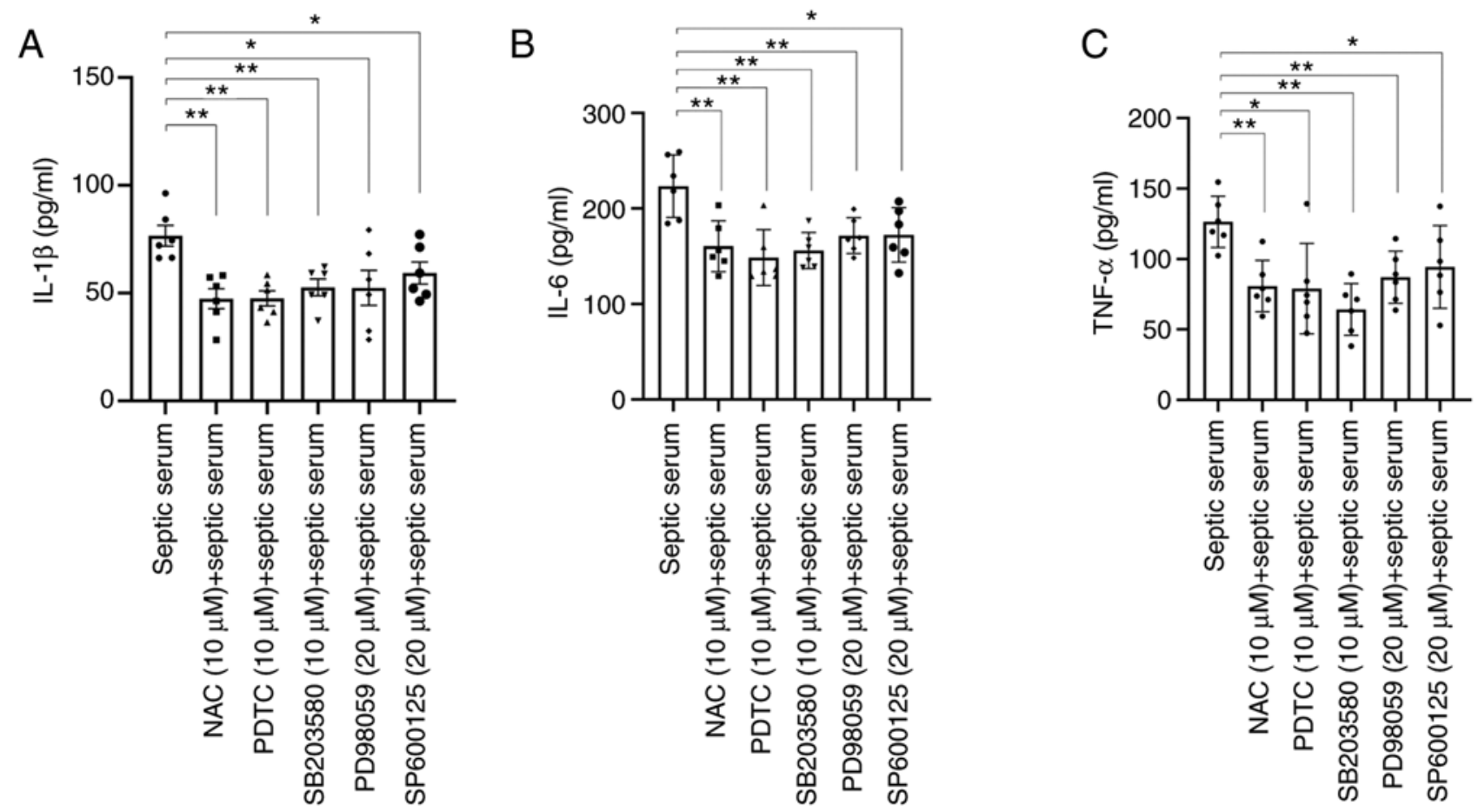

Figure 5. Inflammatory effects of septic serum are mediated by the reactive oxygen species/MAPK/NF- $\mathrm{B}$ signaling pathway in human umbilical vein endothelial cells. (A-C) The cells were treated with septic serum for $12 \mathrm{~h}$ with or without pretreatment with NAC, PD98059, SB203580 or SP600125 for $1 \mathrm{~h}$, and the protein secretion levels of (A) IL-1 $\beta$, (B) IL- 6 and (C) TNF- $\alpha$ were determined by ELISA. Data from six independent experiments are expressed as the mean \pm SEM. ${ }^{*} \mathrm{P}<0.05$ and ${ }^{* *} \mathrm{P}<0.01$. NAC, N-acetylcysteine.

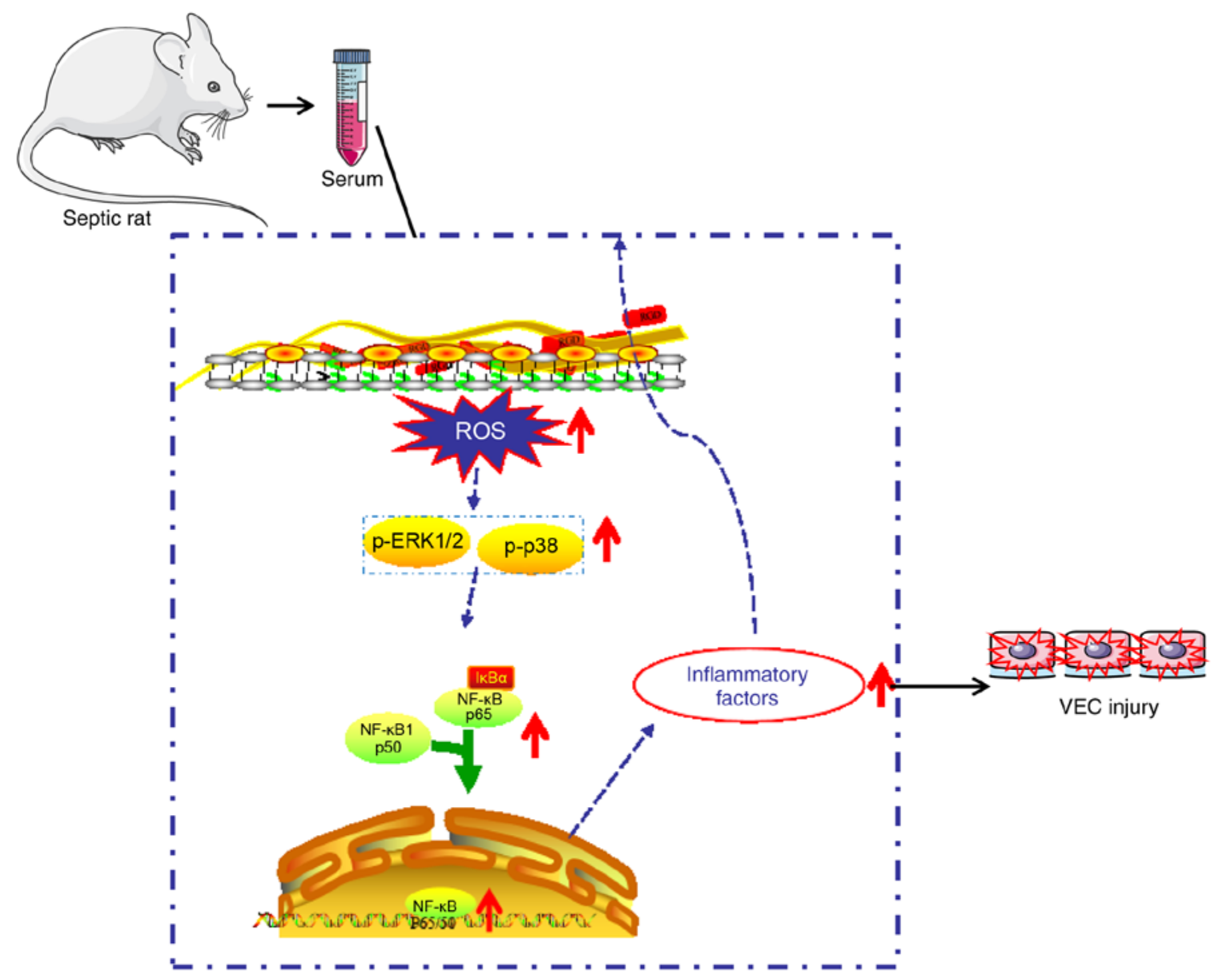

Figure 6. Septic inflammatory injury of serum-induced on human umbilical vein endothelial cells was mediated by increasing the generation of ROS, activating MAPKs and promoting NF-kB transduction. ROS, reactive oxygen species; p-, phosphorylated; VECs, vascular endothelial cells. 
novel strategy for vascular protection and the development of new types of antioxidants, as well as MAPK and NF- $\mathrm{BB}$ inhibitors for the treatment of sepsis.

\section{Acknowledgements}

Not applicable.

\section{Funding}

The present study was supported by the National Training Program of Innovation and Entrepreneurship for Students of China (grant no. 201910716019), the Research Project of the Shaanxi University of Chinese Medicine (grant no. 2020GP19), the Scientific Research Fund Project of Shaanxi Province Department of Education (grant no. 19JK0228) and the Subject Innovation Team of Shaanxi University of Chinese Medicine (grant no. 2019-QN07/132041933).

\section{Availability of data and materials}

The data used and/or analyzed during the present study are available from the corresponding author on reasonable request.

\section{Authors' contributions}

SX and JZ made substantial contributions to the conception and design of the study. YY, ZY and JX acquired, analyzed and interpreted the data. $\mathrm{BQ}, \mathrm{JL}, \mathrm{ZZ}$ and $\mathrm{YH}$ interpreted the data, drafted the article and revised it critically for important intellectual content. All authors read and approved the final manuscript.

\section{Ethics approval and consent to participate}

The experimental protocol was approved by the Institutional Animal Care and Use Committee of the Shaanxi University of Chinese medicine (approval no. 201801115; Xianyang, China).

\section{Patient consent for publication}

Not applicable.

\section{Competing interests}

The authors declare that they have no competing interests.

\section{References}

1. Colbert JF, Schmidt EP, Faubel S and Ginde AA: Severe sepsis outcomes among hospitalizations with inflammatory bowel disease. Shock 47: 128-131, 2017.

2. Cepinskas G and Wilson JX: Inflammatory response in microvascular endothelium in sepsis: Role of oxidants. J Clin Biochem Nutr 42: 175-184, 2008

3. De Blasi RA, Palmisani S, Alampi D, Mercieri M, Romano R, Collini S and Pinto G: Microvascular dysfunction and skeletal muscle oxygenation assessed by phase-modulation near-infrared spectroscopy in patients with septic shock. Intensive Care Med 31: 1661-1668, 2005.

4. Rudd KE, Johnson SC, Agesa KM, Shackelford KA, Tsoi D, Kievlan DR, Colombara DV, Ikuta KS, Kissoon N, Finfer S, et al: Global, regional, and national sepsis incidence and mortality, 1990-2017: Analysis for the global burden of disease study. Lancet 395: 200-211, 2020 .
5. Kumar V: Sepsis roadmap: What we know, what we learned, and where we are going. Clin Immunol 210: 108264, 2020.

6. Martin JB and Badeaux JE: Interpreting Laboratory tests in infection: Making sense of biomarkers in sepsis and systemic inflammatory response syndrome for intensive care unit patients. Crit Care Nurs Clin North Am 29: 119-130, 2017.

7. Edul VK, Ferrara G and Dubin A: Microcirculatory dysfunction in sepsis. Endocr Metab Immune Disord Drug Targets 10: 235-246, 2010.

8. Bro-Jeppesen J, Johansson PI, Kjaergaard J, Wanscher M, Ostrowski SR, Bjerre M and Hassager C: Level of systemic inflammation and endothelial injury is associated with cardiovascular dysfunction and vasopressor support in post-cardiac arrest patients. Resuscitation 121: 179-186, 2017.

9. Iba T and Levy JH: Inflammation and thrombosis: Roles of neutrophils, platelets and endothelial cells and their interactions in thrombus formation during sepsis. J Thromb Haemost 16: 231-241, 2018.

10. Uchimido R, Schmidt EP and Shapiro NI: The glycocalyx: A novel diagnostic and therapeutic target in sepsis. Crit Care 23: $16,2019$.

11. Houschyar KS, Pyles MN, Rein S, Nietzschmann I, Duscher D, Maan ZN, Weissenberg K, Philipps HM, Strauss C, Reichelt B and Siemers F: Continuous hemoadsorption with a cytokine adsorber during sepsis-a review of the literature. Int J Artif Organs 40: 205-211, 2017.

12. Farley KS, Wang LF, Law $C$ and Mehta S: Alveolar macrophage inducible nitric oxide synthase-dependent pulmonary microvascular endothelial cell septic barrier dysfunction. Microvasc Res 76: 208-216, 2008.

13. Berger C, Rossaint J, Van Aken H, Westphal M, Hahnenkamp K and Zarbock A: Lidocaine reduces neutrophil recruitment by abolishing chemokine-induced arrest and transendothelial migration in septic patients. J Immunol 192: 367-376, 2014.

14. Lambertucci F, Motino O, Villar S, Rigalli JP, de Luján Alvarez M, Catania VA, Martín-Sanz P, Carnovale CE, Quiroga AD, Francés DE and Ronco MT: Benznidazole, the trypanocidal drug used for Chagas disease, induces hepatic NRF2 activation and attenuates the inflammatory response in a murine model of sepsis. Toxicol Appl Pharmacol 315: 12-22, 2017.

15. Li HR, Liu J, Zhang SL, Luo T, Wu F, Dong JH, Guo YJ and Zhao L: Corilagin ameliorates the extreme inflammatory status in sepsis through TLR4 signaling pathways. BMC Complement Altern Med 17: 18, 2017

16. Top AP, Ince C, de Meij N, van Dijk M and Tibboel D: Persistent low microcirculatory vessel density in nonsurvivors of sepsis in pediatric intensive care. Crit Care Med 39: 8-13, 2011.

17. O'Sullivan AW, Wang JH and Redmond HP: NF-kappaB and p38 MAPK inhibition improve survival in endotoxin shock and in a cecal ligation and puncture model of sepsis in combination with antibiotic therapy. J Surg Res 152: 46-53, 2009.

18. Rittirsch D, Huber-Lang MS, Flierl MA and Ward PA: Immunodesign of experimental sepsis by cecal ligation and puncture. Nat Protoc 4: 31-36, 2009.

19. Zhao J, Xu SZ and Liu J: Fibrinopeptide A induces C-reactive protein expression through the ROS-ERK1/2/p38-NF- $\kappa$ B signal pathway in the human umbilical vascular endothelial cells. J Cell Physiol 234: 13481-13492, 2019.

20. Livak KJ and Schmittgen TD: Analysis of relative gene expression data using real-time quantitative PCR and the 2(-Delta Delta C(T)) method. Methods 25: 402-408, 2001.

21. Kyriazopoulou E, Leventogiannis K, Norrby-Teglund A, Dimopoulos G, Pantazi A, Orfanos SE, Rovina N, Tsangaris I, Gkavogianni T, Botsa E, et al: Macrophage activation-like syndrome: An immunological entity associated with rapid progression to death in sepsis. BMC Med 15: 172, 2017.

22. Sturtzel C: Endothelial Cells. Adv Exp Med Biol 1003: 71-91, 2017.

23. Garrean S, Gao XP, Brovkovych V, Shimizu J, Zhao YY, Vogel SM and Malik AB: Caveolin-1 regulates NF-kappaB activation and lung inflammatory response to sepsis induced by lipopolysaccharide. J Immunol 177: 4853-4860, 2006.

24. McCuskey RS, Nishida J, McDonnell D, Baker GL, Urbaschek R and Urbaschek B: Effect of immunoglobulin G on the hepatic microvascular inflammatory response during sepsis. Shock 5 : 28-33, 1996.

25. Orfanos SE, Kotanidou A, Glynos C, Athanasiou C, Tsigkos S, Dimopoulou I, Sotiropoulou C, Zakynthinos S, Armaganidis A, Papapetropoulos A and Roussos C: Angiopoietin-2 is increased in severe sepsis: Correlation with inflammatory mediators. Crit Care Med 35: 199-206, 2007. 
26. Yoo JW, Moon JY, Hong SB, Lim CM, Koh Y and Huh JW: Clinical significance of circulating endothelial cells in patients with severe sepsis or septic shock. Infect Dis (Lond) 47: 393-398, 2015.

27. Constantino L, Gonçalves RC, Giombelli VR, Tomasi CD, Vuolo F, Kist LW, de Oliveira GM, de Bittencourt Pasquali MA, Bogo MR, Mauad T, et al: Regulation of lung oxidative damage by endogenous superoxide dismutase in sepsis. Intensive Care Med Exp 2: 17, 2014.

28. Schwalm MT, Pasquali M, Miguel SP, Dos Santos JP Vuolo F, Comim CM, Petronilho F, Quevedo J, Gelain DP, Moreira JC, et al: Acute brain inflammation and oxidative damage are related to long-term cognitive deficits and markers of neurodegeneration in sepsis-survivor rats. Mol Neurobiol 49 380-385, 2014

29. Simon F and Fernández R: Early lipopolysaccharide-induced reactive oxygen species production evokes necrotic cell death in human umbilical vein endothelial cells. J Hypertens 27 $1202-1216,2009$

30. Bime C, Zhou T, Wang T, Slepian MJ, Garcia JG and Hecker L: Reactive oxygen species-associated molecular signature predicts survival in patients with sepsis. Pulm Circ 6: 196-201, 2016.

31. Forrester SJ, Kikuchi DS, Hernandes MS, Xu Q and Griendling KK: Reactive oxygen species in metabolic and inflammatory signaling. Circ Res 122: 877-902, 2018.

32. Zhang J, Wang X, Vikash V, Ye Q, Wu D, Liu Y and Dong W: ROS and ROS-mediated cellular signaling. Oxid Med Cell Longev 2016: 4350965, 2016.

33. Minutoli L, Puzzolo D, Rinaldi M, Irrera N, Marini H, Arcoraci V Bitto A, Crea G, Pisani A, Squadrito F, et al: ROS-mediated NLRP3 inflammasome activation in brain, heart, kidney, and testis ischemia/reperfusion injury. Oxid Med Cell Longev 2016: 2183026, 2016

34. Tejero J, Shiva S and Gladwin MT: Sources of vascular nitric oxide and reactive oxygen species and their regulation. Physiol Rev 99: 311-379, 2019.
35. Mittal M, Siddiqui MR, Tran K, Reddy SP and Malik AB: Reactive oxygen species in inflammation and tissue injury. Antioxid Redox Signal 20: 1126-1167, 2014.

36. Ronco MT, Manarin R, Francés D, Serra E, Revelli S and Carnovale C: Benznidazole treatment attenuates liver NF- $\kappa \mathrm{B}$ activity and MAPK in a cecal ligation and puncture model of sepsis. Mol Immunol 48: 867-873, 2011.

37. Song GY, Chung CS, Chaudry IH and Ayala A: Immune suppression in polymicrobial sepsis: Differential regulation of Th1 and Th2 responses by p38 MAPK. J Surg Res 91: 141-146, 2000.

38. Song GY, Chung CS, Jarrar D, Chaudry IH and Ayala A: Evolution of an immune suppressive macrophage phenotype as a product of P38 MAPK activation in polymicrobial sepsis. Shock 15: 42-48, 2001.

39. Song GY, Chung CS, Jarrar D, Cioffi WG and Ayala A: Mechanism of immune dysfunction in sepsis: Inducible nitric oxide-meditated alterations in p38 MAPK activation. J Trauma 53: 276-282, 2002.

40. Sun Y, Li YH, Wu XX, Zheng W, Guo ZH, Li Y, Chen T, Hua ZC and Xu Q: Ethanol extract from Artemisia vestita, a traditional Tibetan medicine, exerts anti-sepsis action through down-regulating the MAPK and NF- $\mathrm{BB}$ pathways. Int J Mol Med 17: 957-962, 2006

41. Kim WH, An HJ, Kim JY, Gwon MG, Gu H, Lee SJ, Park JY, Park KD, Han SM, Kim MK and Park KK: Apamin inhibits TNF- $\alpha$ - and IFN- $\gamma$-induced inflammatory cytokines and chemokines via suppressions of NF- $\kappa$ B signaling pathway and STAT in human keratinocytes. Pharmacol Rep 69: 1030-1035, 2017.

42. Thoma A and Lightfoot AP: NF- $\mathrm{B}$ B and inflammatory cytokine signalling: Role in skeletal muscle atrophy. Adv Exp Med Biol 1088: 267-279, 2018

(i) $(9)$ This work is licensed under a Creative Commons Attribution-NonCommercial-NoDerivatives 4.0 International (CC BY-NC-ND 4.0) License. 